University of Nebraska - Lincoln

DigitalCommons@University of Nebraska - Lincoln

Faculty Publications: Department of

Entomology

Entomology, Department of

June 2003

\title{
Resistance Status of House Flies (Diptera: Muscidae) from Southeastern Nebraska Beef Cattle Feedlots to Selected Insecticides
}

\author{
Paula C.R.G. Marcon \\ University of Nebraska-Lincoln \\ Gustave D. Thomas \\ University of Nebraska-Lincoln \\ Blair D. Siegfried \\ University of Nebraska-Lincoln, bsiegfried1@ufl.edu \\ John B. Campbell \\ University of Nebraska-Lincoln \\ Steven R. Skoda \\ University of Nebraska-Lincoln, sskoda1@unl.edu
}

Follow this and additional works at: https://digitalcommons.unl.edu/entomologyfacpub

Part of the Entomology Commons

\begin{abstract}
Marcon, Paula C.R.G.; Thomas, Gustave D.; Siegfried, Blair D.; Campbell, John B.; and Skoda, Steven R., "Resistance Status of House Flies (Diptera: Muscidae) from Southeastern Nebraska Beef Cattle Feedlots to Selected Insecticides" (2003). Faculty Publications: Department of Entomology. 43.

https://digitalcommons.unl.edu/entomologyfacpub/43
\end{abstract}

This Article is brought to you for free and open access by the Entomology, Department of at DigitalCommons@University of Nebraska - Lincoln. It has been accepted for inclusion in Faculty Publications: Department of Entomology by an authorized administrator of DigitalCommons@University of Nebraska - Lincoln. 


\title{
Resistance Status of House Flies (Diptera: \\ Muscidae) from Southeastern Nebraska Beef Cattle Feedlots to Selected Insecticides
}

\author{
Paula C.R.G. Marçon, Gustave D. Thomas, Blair D. Siegfried, John B. \\ Campell, and Steven R. Skoda
}

Journal of Economic Entomology

Volume 96, Issue 3 (June 2003) pp. 1016-1020

DOI: 10.1603/0022-0493(2003)096[1016:RSOHFD]2.0.CO;2

[Authors may post electronic reprints of their own journal articles after an embargo period of two years has passed from the date of publication. Also, authors must include on the electronic reprint the following statement: ]

This article is the copyright property of the Entomological Society of America and may not be used for any commercial or other private purpose without specific written permission of the Entomological Society of America. 


\title{
Resistance Status of House Flies (Diptera: Muscidae) from Southeastern Nebraska Beef Cattle Feedlots to Selected Insecticides
}

\author{
PAULA C.R.G. MARÇON ${ }^{1}$ GUSTAVE D. THOMAS,${ }^{2}$ BLAIR D. SIEGFRIED ${ }^{3}$ \\ JOHN B. CAMPBELL, ${ }^{4}$ AND STEVEN R. SKODA ${ }^{2}$
}

\begin{abstract}
J. Econ. Entomol. 96(3): 1016-1020 (2003)
ABSTRACT The status of resistance to three insecticides (permethrin, stirofos, and methoxychlor), relative to a laboratory-susceptible colony, was evaluated in field populations of house flies, Musca domestica L., collected from two beef cattle feedlots in southeastern Nebraska. Topical application and residual exposure to treated glass surfaces were suitable methods for determining the resistance status of house flies to permethrin, stirofos, or methoxychlor. However, in most cases, residual exposure was more sensitive in resistance detection (i.e., higher resistance ratios). The field populations tested were moderately resistant to permethrin $(\mathrm{RR}=4.9$-fold and $\mathrm{RR}=7.3$-fold, for topical application and residual exposure, respectively) and extremely resistant to stirofos and methoxychlor (not accurately quantifiable because of low mortality at the highest possible concentrations or doses). Probable explanations for the resistance status of these house fly populations and implications for global feedlot fly management are discussed.
\end{abstract}

KEY WORDS Musca domestica, insecticide resistance, bioassay, permethrin, stirofos, methoxychlor

THE HOUSE FLY, Musca domestica L., is an important pest of humans and domesticated animals and is also a vector of both human and animal diseases. Greenberg (1971) lists more than 100 pathogen species harbored by house flies, and, of these, 65 are known to be transmitted by the flies. More recently, house flies have been shown to vector enterohemorrhagic colitis caused by Escherichia coli 0157:H7 and Yersinia pseudotuberculosis (Sasaki et al. 2000 and Zurek et al. 2001). The fly breeds in filth of all kinds, and it is often the primary cause of lawsuits in areas in which urban growth infringes upon agricultural areas, a fact that has greatly increased the pressure on livestock operators to effectively control house fly populations (Thomas and Skoda 1993). Historically, house fly management has been directed at adult populations and relied heavily on chemical control (Campbell 1993). However, the use of insecticides in house fly management programs is becoming more costly, more regulated, and less effective because of resistance problems (Ge-

This article reports the results of research only. Mention of a proprietary product does not constitute endorsement or a recommendation for its use by the USDA.

${ }^{1}$ Current address: Dupont Productos Agricolas Estacao Experimental Agricola, Rua Bortola Ferro, No. 500 Paulina SP 13140-000 Brazil.

${ }^{2}$ Midwest Livestock Insects Res. Laboratory, USDA-ARS, 305 Plant Industry Building, University of Nebraska - Lincoln, Lincoln, NE 68583-0938.

${ }^{3}$ Department of Entomology, University of Nebraska, Lincoln, NE 68583-0938

${ }^{4}$ University of Nebraska, West Central Research and Extension Center, 461 West University Drive, North Platte, NE 69101-7756 (e-mail: jcampbell1@unl.edu). den et al. 1992). The chronological sequence of pesticide use for control of livestock insects in Nebraska included the chlorinated hydrocarbons such as DDT and methoxychlor in the 1950s and 1960s, the phosphates in the late 1960s and 1970s, including tetrachlorvos, naled, and dichlorvos. Since the late 1980s, pyrethroids have largely replaced the phosphates. Permethrin and fenvalerate were used in ear tags for horn fly control until resistance developed, and permethrin is widely used for house fly and stable fly control at feedlots, dairies, swine, and poultry units.

Although the house fly has demonstrated the ability to develop resistance to most insecticides approved for use against it (Bull and Pryor 1991), it is certainly not resistant throughout its geographic range. Susceptible populations exist (Scott et al. 1989), and regional assessment of susceptibility of local populations of house flies to different insecticides can yield important information for integrated fly control programs that use available insecticides in ways that minimize resistance problems. Pospischil et al. (1996) reported multiresistance in German house fly populations selected from regions with known control problems to pyrethroids, organophosphates, and carbamate insecticides. Scott et al. (2000) found considerable insecticide resistance variation in house fly populations collected from New York caged layer poultry houses. Overall, there was correlation between insecticide use histories and levels of resistance. Kaufman et al. (2001), however, found little variation in resistance levels in fly populations at New York dairy farms. The highest levels of resistance in fly populations collected from both poultry and dairy units was tetrachlorin- 
phos, permethrin, and cyfluthrin. Kristensen et al. (2001) also reported considerable variation in insecticide resistance in house fly populations collected from Danish farms with high resistance to pyrethroid organophosphate and carbamate insecticides in some house fly populations.

In assessing pest resistance to pesticides, it is important to use bioassay procedures that are sensitive enough to detect changes in susceptibility status of field populations as they occur. In this study, a direct contact and a residual bioassay were compared with the objective of determining the susceptibility of field populations of house flies from southeastern Nebraska to a pyrethroid (permethrin), an organophosphate (stirofos), and a chlorinated hydrocarbon (methoxychlor).

\section{Materials and Methods}

Insecticides. All insecticides used were technical grade and diluted in acetone. Permethrin (94.6\% [AI]) maximum $55 \% \pm$ cis and minimum $45 \% \pm$ trans) was provided by FMC Corp. (Philadelphia, PA), stirofos (99\% [AI]) was supplied by Fermenta Animal Health (Kansas City, MO), and methoxychlor $(95.6 \%$ [AI]) was obtained from Kincaid Enterprise (Nitro, WV).

House Flies. The insecticide-susceptible laboratory colony of house flies used in this study originated from the Beltsville W Strain (Livestock Insects Laboratory, Beltsville, MD). This strain was used as a standard reference for insecticide susceptibility because it has been isolated from insecticide exposure since 1969 (Pickens et al. 1972). House flies were collected from two counties in southeastern Nebraska: feedlot A in Saunders County and feedlot B in Lancaster County. Feedlot A had a record of recent insecticide use (adult fly control with permethrin using a mist blower), whereas feedlot B had not been sprayed for $2 \mathrm{yr}$. We were unable to obtain accurate historical records of insecticide applications from other cattle feeders in the region, although we determined that use of insecticides for fly control was minimal.

Field populations of house flies were used for the resistance bioassay because we felt they represented the situation at the time of collection. Adult house flies were collected by sweeping with an insect net, mostly around feedbunks but also in the general feedlot area. After collection, flies were transferred immediately to cages and transported to the laboratory. Bioassays were performed on the same day as capture, usually within $2 \mathrm{~h}$. Both 3-5-d males and females were used in the bioassays, representing a random sample from field collections. Insecticide-susceptible laboratory flies were tested. After treatment, test insects were maintained at $25^{\circ} \mathrm{C} \pm 1{ }^{\circ} \mathrm{C}$ and photoperiod of $12: 12 \mathrm{~h}$ (L:D).

Topical Exposure. House flies were separated into groups of 15 and placed in disposable cups before treatment. Cups containing 15 flies were assigned randomly to each of three tests, and within a test, to each dose treatment. Each bioassay consisted of three complete tests using three groups of 15 flies from each population for each treatment level in a test. For each test, serial dilutions were prepared from a stock solution to produce $5-10$ dose levels. Dose ranges for each insecticide varied depending on the populations being tested. For permethrin, the doses used to test the susceptible population ranged from 0 to $0.05 \mu \mathrm{g} / \mathrm{fly}$, and the doses used to test the field populations ranged from 0 to $0.25 \mu \mathrm{g} /$ fly. For stirofos, doses ranged from 0 to $0.38 \mu \mathrm{g} / \mathrm{fly}$ (susceptible) and from 0 to 193.0 $\mu \mathrm{g} /$ fly (field). For methoxychlor, doses ranged from 0 to $7.77 \mu \mathrm{g} / \mathrm{fly}$ (susceptible) and from 0 to $608.0 \mu \mathrm{g} / \mathrm{fly}$ (field). Acetone was used as the solvent for all the insecticides. All serial dilutions were prepared the day before being used.

Flies were anesthetized with $\mathrm{CO}_{2}$ and $1 \mu \mathrm{l}$ of the appropriate solution was applied to the notum of each fly using an Eppendorf micropipette $(0.5-10.0 \mu \mathrm{l}$, Brinkmann Instruments, Westbury, NY). Controls were treated with acetone only. After treatment, flies were placed in paper cups $(114 \mathrm{ml})$ that were covered with tulle cloth and secured with rubber bands. A water-saturated dental wick was placed on the bottom of each cup.

Each time a field fly population was tested, a simultaneous test was performed on the reference susceptible laboratory population. Before each bioassay, a sample of $\approx 100$ house flies was weighed to determine mean weights for each population on each bioassay date. This allowed us to convert lethal dose values from micrograms per fly to micrograms per milligram of body weight.

Residual Exposure. Serial dilutions were prepared from a stock solution to produce 5-10 insecticide concentrations. Acetone was used as the solvent for all insecticides. Each bioassay consisted of three complete tests using three groups of 20 flies from each population for each treatment level in a test. Concentration ranges for each insecticide varied depending on the population being tested. For permethrin, the concentrations used to test the susceptible population ranged from 0 to $0.12 \mu \mathrm{g} / \mathrm{cm}^{2}$, and the concentrations used to test the field populations ranged from 0 to 6.0 $\mu \mathrm{g} / \mathrm{cm}^{2}$. For stirofos, concentrations ranged from 0 to $2.0 \mu \mathrm{g} / \mathrm{cm}^{2}$ (susceptible) and from 0 to $3,000.0 \mu \mathrm{g} / \mathrm{cm}^{2}$ (field). For methoxychlor, concentrations ranged from 0 to $2.0 \mu \mathrm{g} /$ fly (susceptible) and from 0 to $12,000.0 \mu \mathrm{g} / \mathrm{cm}^{2}$ (field). Standard glass Petri dishes were used (interior bottom diameter of $9 \mathrm{~cm}$ ). For each concentration, $2 \mathrm{ml}$ of the appropriate dilution was applied to the bottoms of three Petri dishes and distributed uniformly by gently rotating the dishes while drying. Acetone alone was applied in a similar manner to each of three control dishes. After treatment, the dishes were allowed to air dry for $3 \mathrm{~h}$ and then covered and stored in darkness at room temperature for at least $24 \mathrm{~h}$ before use (no longer than $1 \mathrm{wk}$ ).

Before each bioassay, test flies were anesthetized using $\mathrm{CO}_{2}$, separated into groups of 20 and placed into small, screened containers. After all insects had been grouped, flies were anesthetized lightly again and placed in the respective Petri dishes. Test flies were placed on the untreated Petri dish cover to allow them 
Table 1. Comparative toxicity of selected insecticides to house flies from southeastern Nebraska

\begin{tabular}{|c|c|c|c|c|c|c|}
\hline Insecticide & Technique & Population & $n$ & Slope \pm SE & $\begin{array}{l}\text { LD50 }\left(\text { FL95\%) }{ }^{a}\right. \\
\text { LC50 }(\text { FL95\%) }\end{array}$ & RR \\
\hline \multirow[t]{8}{*}{ Permethrin } & \multirow[t]{4}{*}{ Topical exposure } & Susceptible & 360 & $4.16 \pm 0.39$ & $0.0007(0.0006-0.0008)$ & - \\
\hline & & Feedlot A & 356 & $2.73 \pm 0.28$ & $0.0034(0.0021-0.0051)$ & $4.9^{*}$ \\
\hline & & Susceptible & 315 & $6.92 \pm 0.82$ & $0.0005(0.0005-0.0006)$ & - \\
\hline & & Feedlot B & 267 & $2.67 \pm 0.33$ & $0.0019(0.0014-0.0025)$ & $3.8^{*}$ \\
\hline & \multirow[t]{4}{*}{ Residual exposure } & Susceptible & 473 & $4.65 \pm 0.39$ & $0.027(0.022-0.032)$ & - \\
\hline & & Feedlot A & 519 & $3.24 \pm 0.30$ & $0.198(0.172-0.228)$ & $7.3^{*}$ \\
\hline & & Susceptible & 480 & $4.77 \pm 0.41$ & $0.026(0.023-0.028)$ & - \\
\hline & & FeedlotB & 480 & $3.37 \pm 0.30$ & $0.182(0.153-0.216)$ & $7.0 *$ \\
\hline \multirow[t]{6}{*}{ Stirofos } & \multirow[t]{3}{*}{ Topical exposure $^{c}$} & Susceptible & 315 & $2.78 \pm 0.27$ & $0.0025(0.0016-0.0040)$ & - \\
\hline & & Feedlot A & 356 & - & $<17.63-$ & $>7,100$ \\
\hline & & Feedlot B & 267 & - & $>6.40-$ & $>2,560$ \\
\hline & \multirow[t]{3}{*}{ Residual exposure $^{c}$} & Susceptible & 420 & $2.86 \pm 0.27$ & $0.151(0.064-0.270)$ & - \\
\hline & & Feedlot A & 357 & - & $>3,000-$ & $>20,000$ \\
\hline & & Feedlot B & 359 & - & $>3,000-$ & $>20,000$ \\
\hline \multirow[t]{6}{*}{ Methoxychlor } & \multirow[t]{3}{*}{ Topical exposure ${ }^{c}$} & Susceptible & 360 & $2.22 \pm 0.20$ & $0.0592(0.0472-0.0743)$ & - \\
\hline & & Feedlot A & 270 & - & $>55.10-$ & $>930.0$ \\
\hline & & Feedlot B & 238 & - & $>20.42-$ & $>345.0$ \\
\hline & \multirow[t]{3}{*}{ Residual exposure } & Susceptible & 357 & $1.93 \pm 0.18$ & $1.590(1.010-2.430)$ & - \\
\hline & & Feedlot A & 410 & $1.54 \pm 0.21$ & $150.9(79.8-245.9)$ & $94.9^{*}$ \\
\hline & & Feedlot B & 410 & $2.00 \pm 0.22$ & $207.5(156.2-279.7)$ & $130.5^{*}$ \\
\hline
\end{tabular}

Resistance ratio $(\mathrm{RR})=$ lethal concentration $(\mathrm{LC})$ or lethal dose (LD) value of the field population divided by the corresponding value of the reference susceptible population.

* Resistance ratio significantly $>1.0(P>0.050)$, as determined by the likelihood test for equality of the lethal concentration or lethal dose values used to calculate the ratio, followed by pairwise comparisons using nonoverlaping fiducial limits (Savin et al. 1977).

${ }^{a}$ Micrograms (AI) / mg fly body weight.

${ }^{b}$ Micrograms (AI) $/ \mathrm{cm}^{2}$.

${ }^{c}$ Maximal concentration (residual exposure) or dose (topical application) of stirofos and methoxychlor produced less than $50 \%$ mortality in the field house fly populations tested. Therefore, probit slopes were generated only for the susceptible laboratory colony.

to recover from anesthesia. Each Petri dish was provided with a water-saturated dental wick placed on the Petri dish bottom. Each time a field population was tested, a simultaneous test was performed on the reference susceptible population.

Data Collection and Statistical Analysis. For both exposure techniques, mortality was recorded at 2, 4, and $24 \mathrm{~h}$ after exposure. Flies unable to stand upright were recorded as dead. Dose-mortality data were subjected to probit analysis (Finney 1971) using POLO-PC (LeOra Software 1987). Resistance ratios were calculated by dividing the lethal concentration value (residual exposure) or lethal dose value (topical treatment) of field populations by the corresponding value of the reference susceptible population. Significance of differences was determined by the likelihood test for equality of the lethal concentration or lethal dose values used to compute the ratios, followed by pairwise comparisons using nonoverlapping fiducial limits (Savin et al. 1977).

\section{Results}

For both exposure to residues on glass and topical applications, insecticide exposure of house flies for $4 \mathrm{~h}$ produced less variable results than when flies were exposed for only $2 \mathrm{~h}$. The 24 -h exposure period resulted in high control mortality $(>30 \%)$ of field-collected flies in many of the bioassays, regardless of technique. Therefore, only results from the 4-h exposure are presented.

Moderate levels of resistance to permethrin were found in house flies from the two feedlots sampled
(Table 1). Residual exposure to permethrin on glass allowed for better discrimination between susceptible and resistant individuals which is reflected by the higher resistance ratios (7.3 and 7.0, for feedlots $\mathrm{A}$ and $\mathrm{B}$, respectively) as compared with those obtained when the same populations were tested by topical application (4.9 and 3.8, for feedlots A and B, respectively). The insecticide mortality response of house flies from feedlot A was not significantly different from that of house flies from feedlot B.

The field populations tested were extremely resistant to stirofos, whether exposed to insecticide residues on glass or treated topically (Table 1). Insufficient data did not allow the development of significant regression lines because of low mortality $(<50 \%)$ at the highest concentrations (residual exposure) or doses (topical exposure) tested, which were at least 20,000-fold higher than the $\mathrm{LC}_{50}$ and 2,560-fold higher than the $\mathrm{LD}_{50}$ of the susceptible laboratory colony that was tested simultaneously. Similar to observations with permethrin, the residual exposure provided higher relative resistance ratios.

Resistance to methoxychlor was also very high, both when flies were challenged with residues or by topical application of the insecticide. Dose-response lines could not be generated using topical applications because of low mortality $(<50 \%)$ at the highest dose tested, $608 \mu \mathrm{g} / \mathrm{fly}$ (i.e., $55.1 \mu \mathrm{g} / \mathrm{mg}$ body weight for flies from feedlot A). This was 930-fold higher than the $\mathrm{LD}_{50}$ of the simultaneously tested susceptible population. Although quantification of resistance to methoxychlor was not possible using this technique, resistance ratios were at least $>930$ and $>345$ for flies 
from feedlots A and B, respectively. The resistance ratios generated for residue assays were 94.5 and 130.5 for feedlots A and B. These data suggest that field populations of house flies were less tolerant to residual contact than they were to direct topical application of Methoxychlor, which is contrary to what was observed for the other two insecticides.

\section{Discussion}

Moderate levels of resistance to permethrin were detected in the field-collected house flies from both feedlots using both topical applications or exposure to residues on glass. Farham et al. (1984) have correlated data from topical applications of permethrin and control failures in the field and found that control failures usually occur only when resistance ratios are $>15$ fold. In our study, the greatest resistance ratio observed was $<5$-fold, which suggests that permethrin should still be an effective insecticide for control of these house fly populations.

The field populations tested were extremely resistant to both stirofos and methoxychlor. Accurate quantification of resistance was not possible because of low mortality at the highest possible concentrations or doses. Therefore, it is reasonable to infer that the house fly populations tested are minimally affected by stirofos and methoxychlor, either as residues or direct application, and that adult house fly control with either of these insecticides would be largely ineffective. Cross-resistance to other organophosphate or chlorinated hydrocarbons is probable and should be investigated. It is probably not surprising that these house fly populations were resistant to methoxychlor and stirofos. Methoxychlor is a representative of the organchlorine insecticide group, and these were widely used for livestock insect control in the 1960s and 1970s, but is no longer in use, although still registered. Stirophos is an organophosphate insecticide, and these products were popular in the 1980s. Permethrin, a pyrethroid, became a popular livestock insect product in the late 1980s and is still popular today.

In preliminary experiments, exposure of house flies to insecticide residues on filter paper was attempted. However, this technique proved to be inappropriate because little or no mortality was observed in the susceptible laboratory population even at very high concentrations, especially for stirofos and methoxychlor. Apparently, these insecticides became bound to the filter paper thereby preventing exposure of the flies. Significant concentration-response regressions were generated only for permethrin, but the amount of insecticide applied to the filter paper had to be at least 1000-fold higher than residues on glass to elicit a response from the susceptible population. Similar results were observed in another study with stable flies, and a more detailed explanation of the difficulties of this technique is presented elsewhere (Marcon et al. 1997).

Both exposure to residues on glass Petri dishes and topical applications provided suitable results for testing the susceptibility of house flies to permethrin and stirofos. However, a comparison of the resistance ratios across techniques suggested that residual exposure to these two insecticides allows for greater expression of resistance compared with topical exposure. Therefore, it should allow for better discrimination between susceptible and resistant phenotypes (Dennehey et al. 1983). It is important to recognize that residues on glass more closely approximate the mode of exposure of flies to residual insecticides in feedlots. Also, this technique allows for dishes to be prepared in advance and sent to different locations for testing. Development of a diagnostic bioassay using residues on glass should significantly improve the efficiency of this technique in resistance monitoring (Kaufman et al. 2001).

For methoxychlor, the situation seemed to be reversed; that is, topically applied methoxychlor generated higher resistance ratios than did exposure to residues on glass. These results were not unexpected because during the course of the experiments, it was noted that the flies challenged with very high concentrations of methoxychlor on glass became entrapped in the accumulated residues, which most likely contributed to the observed mortality. This problem was not observed for the susceptible laboratory colony because much lower concentrations were needed to generate significant concentration-response curves. This apparent limitation of the technique should only be of concern if quantification of resistance is essential. For detection of resistance using a diagnostic concentration that discriminates between resistant and susceptible individuals, exposure to methoxychlor residues on glass should be a useful technique.

Insecticide susceptibility of these house fly populations greatly contrasts with that of stable flies collected at the same feedlots (Marcon et al. 1997), the latter being highly susceptible to permethrin, stirofos, and methoxychlor. As far as we were able to ascertain, recent insecticide use was minimal at the feedlots sampled. Therefore, the coexistence of highly resistant house fly populations and susceptible stable fly populations in the same feedlots may indicate a greater propensity for dispersal of house flies from areas with higher resistance frequencies.

Boxler and Campbell (1983) found a similar situation with house fly resistance to dichlorvos, which indicated movement of house flies between feedlots. Lysyk and Axtell (1986), in a capture-mark-releaserecapture study, found considerable movement of house flies between poultry houses and dairies and into habitats that did not contain house fly breeding or feeding material. Their study indicates that house fly dispersal is considerable, even when habitats seem ideal. Methoxychlor and stirofos resistance may have been retained in the house fly populations as a result of lack of biotic potential disadvantages associated with resistance (Roush and Plapp 1982). However, insecticide resistance may not necessarily be associated with application exposure at the feedlots, but rather the result of migration of resistant house flies into these areas: house flies are more intensely ex- 
posed to chemical treatments in domestic settings, and resistant individuals may move to feedlot areas.

These points have important implications for insecticide resistance management because, in practice, pest control efforts are generally the same for both species of flies (Campbell 1993). Further studies are needed to understand the relationship between insecticide resistance, biotic potential, and migration patterns of these two muscid species if we are to design effective control strategies for these pests. Furthermore, monitoring of feedlot fly populations for insecticide resistance should continue not only for the insecticides currently used but also for new insecticides that are developed for cattle pests control. Detecting cross-resistance to new insecticides before they are in common use would be beneficial to both the cattle industry and the insecticide industry. Also, detecting the loss of resistance to currently used insecticides, if it occurs, could be beneficial in developing future pest management strategies.

\section{Acknowledgments}

We thank R. Miller, retired (formerly Livestock Insects Laboratory, Beltsville, MD) for providing insecticide-susceptible house flies for this study and H. R. Meyer (Department of Entomology, North Dakota State University, Fargo) for supplying insecticides and for the treatment of the filter papers. The authors appreciate the technical assistance of D. Berkebile and T. Spencer. This study was conducted in cooperation with the Institute of Agriculture and Natural Resources, University of Nebraska, Lincoln, NE. Published as paper No. 11864, Journal Series, NE Agricultural Research Division and contribution 947 of the Department of Entomology, University of Nebraska, Lincoln.

\section{References Cited}

Boxler, D. J., and J. B. Campbell. 1983. Survey of resistance of house fly Musca domestica (L.), to dichlorvos in Nebraska feedlots. J. Kans. Entomol. Soc. 56: 159-163.

Bull, D. L., and N. W. Pryor. 1991. Interactions of carbaryl with susceptible and multi-resistant house flies (Diptera: Muscidae). J. Econ. Entomol. 84: 1145-1153.

Campbell, J. B. 1993. The economics of the fly problem, pp. 34-39. In G. D. Thomas and S. R. Skoda [eds.] . Rural flies in the urban environment? North Central Regional Research Bulletin No. 335, Institute of Agriculture and Natural Resources Research Bulletin No. 317, University of Nebraska Agricultural Research Division, Lincoln.

Dennehey, T. J., J. Granett, and T. F. Leigh. 1983. Relevance of slide-dip and residual bioassay comparisons to detection of resistance in spider mites. J. Econ. Entomol. 80: $706-715$.

Farham, A. W., K. E. O’Dell, I. Denholm, and R. M. Sawicki. 1984. Factors affecting resistance to insecticides in house flies, Musca domestica L. (Diptera: Muscidae). III. Relationship between the level of resistance of pyrethroids, control failure in the field and the frequency of gene $\mathrm{Kdr}$. Bull. Entomol. Res. 74: 581-589.
Finney, D. J. 1971. Probit analysis. Cambridge University Press, Cambridge.

Geden, C. J., D. A. Rutz, J. G. Scott, and S. J. Long. 1992. Susceptibility of house flies (Diptera: Muscidae) and five pupal parasitoids (Hymenoptera: Pteromalidae) to abamectin and seven commercial insecticides. J. Econ. Entomol. 85: 435-440.

Greenberg, B. 1971. Flies and disease, vol. II. Biology and disease transmission. Princeton University Press, Princeton, $\mathrm{NJ}$.

Kaufman, P. E., J. G. Scott, and D. A. Rutz. 2001. Monitoring insecticide resistance in house flies (Diptera: Muscidae) from New York dairies. Pest Manag. Sci. 57: 514-521.

Kristensen, M., A. G. Spencer, and J. B. Jespersen. 2001. The status and development of insecticide resistance in Danish populations of the house fly Musca domestica L. Pest Manag. Sci. 57: 82-89.

LeOra Software. 1987. POLO-PC. A user's guide to probit analysis or logit analysis. LeOra Software, Berkeley, CA.

Lysyk, T. J., and R. E. Axtell. 1986. Movement and distribution of house flies (Diptera: Muscidae) between two livestock farms. J. Econ. Entomol. 79: 993-998.

Marcon, P.C.R.G., G. D. Thomas, B. D. Siegfried, and J. B. Campbell. 1997. Susceptibility of stable flies (Diptera: Muscidae) from southern Nebraska beef cattle feedlots to selected insecticides and comparison of 3 bioassay techniques. J. Econ. Entomol. 90: 293-298.

Pickens, L. G., R. W. Miller Jr., and D. L. Bailey. 1972. Cross-resistance to rabon in the house fly pressured with diazinon in the field and in the laboratory. J. Econ. Entomol. 65: 6-8.

Pospischil, R., K. Szomm, M Londershausen, M. Schroder, A. Tuberg, and R. Fuchs. 1996. Multiple resistance in larger house fly Musca domestica in Germany. Pestic. Sci. 48: 333-41.

Roush, R. T., and F. W. Plapp,Jr. 1982. Effects of insecticide resistance on biotic potential of the house fly (Diptera: Muscidae). J. Econ. Entomol. 75: 708-713.

Sasaki, T., M. Kobayashi, and N. Agui. 2000. Epidemiological potential of excretion and regurgitation by Musca domestica (Diptera: Muscidae) in the dissemination of Escherichia Coli. 0157:H7 to food. J. Med. Entomol. 37: 945-949.

Savin, N. E., J. L. Robertson, and R. M. Russell. 1977. A critical evaluation of bioassay in insecticide research: likelihood ratio tests of dose-mortality regression. Bull. Entomol. Soc. Am. 23: 257-266.

Scott, J. G., T. G. Alefontis, P. E. Kaufman, and D. A. Rutz. 2000. Insecticide resistance in house flies from cagedlayer poultry facilities. Pest. Manag. Sci. 56: 147-153.

Scott, J. G., R. T. Roush, and D. A. Rutz. 1989. Insecticide resistance of house flies from New York dairies (Diptera: Muscidae). J. Agric. Entomol. 6: 53-64.

Thomas, G. D., and S. R. Skoda [eds.]. 1993. Rural flies in the urban environment? North Central Regional Research Bulletin No. 335, Institute of Agriculture and Natural Resources Research Bulletin No. 317, University of Nebraska Agricultural Research Division, Lincoln.

Zurek, L., S. S. Denning, C. Schal, and D. W. Watson. 2001. Vector competence of Musca domestica (Diptera: Muscidae) for Yersinia pseudotuberculosis. J. Med. Entomol. 38: 333-335.

Received for publication 13 February 2002; accepted 20 December 2002. 